\title{
Stress-induced cardiomyopathy (Takotsubo) - broken heart and mind?
}

\author{
This article was published in the following Dove Press journal: \\ Vascular Health and Risk Management \\ 16 April 2013 \\ Number of times this article has been viewed
}

\author{
Björn Redfors \\ Yangzhen Shao \\ Elmir Omerovic \\ Department of Molecular and Clinical \\ Medicine, Sahlgrenska Academy \\ at University of Gothenburg, \\ Gothenburg, Sweden
}

\begin{abstract}
Stress-induced cardiomyopathy (SIC), also known as Takotsubo cardiomyopathy, is characterized by severe but potentially reversible regional left ventricular wall motion abnormalities, ie, akinesia, in the absence of explanatory angiographic evidence of a coronary occlusion. The typical pattern is that of an akinetic apex with preserved contractions in the base, but other variants are also common, including basal or midmyocardial akinesia with preserved apical function. The pathophysiology of SIC remains largely unknown but catecholamines are believed to play a pivotal role. The diverse array of triggering events that have been linked to SIC are arbitrarily categorized as either emotional or somatic stressors. These categories can be considered as different elements of a continuous spectrum, linked through the interface of neurology and psychiatry. This paper reviews our current knowledge of SIC, with focus on the intimate relationship between the brain and the heart.
\end{abstract}

Keywords: stress-induced cardiomyopathy, takotsubo cardiomyopathy, catecholamine, cerebral injury, emotional stress, somatic stress

\section{Introduction}

Stress-induced cardiomyopathy (SIC), also known as Takotsubo cardiomyopathy, broken heart syndrome, ampulla cardiomyopathy, and apical ballooning syndrome, was first recognized in Japan almost twenty years ago. Since then, more than 1500 reports on the subject have been published, and an increasing amount of articles are published each year. ${ }^{1}$ Approximately $90 \%$ of reported SIC patients were women. ${ }^{1,2}$ As the name of this syndrome implies, a preceding somatic and/or emotional stressor can be identified in a majority of the patients (Table 1). ${ }^{1,3}$ Since its recognition, SIC has emerged as a rather common entity and is an important differential diagnosis in patients with chest pain. The characteristic hallmark is potentially reversible regional left-ventricular wall motion abnormality, ie, akinesia, in the absence of explanatory angiographic evidence of a coronary occlusion. ${ }^{4}$ The typical pattern is that of an akinetic apex with preserved contractions in the base (Figure 1), but other variants are also common, including basal or midmyocardial akinesia with preserved apical function. ${ }^{1}$ SIC is associated with electrocardiogram (ECG) changes indicative of ischemia and elevated plasma levels of cardiac proteins. Although several attempts have been made to distinguish between SIC and acute myocardial infarction, based on noninvasive diagnostic criteria, as of yet, these two conditions can only reliably be distinguished by invasive procedures, ie, absence of explanatory coronary lesions on the angiogram. . $^{5,6}$ The etiology, epidemiology, and pathophysiology of SIC remain largely unknown, but catecholamines are believed to play a pivotal role. Among the evidence suggesting
Correspondence: Björn Redfors

The Wallenberg Laboratory at Sahlgrenska Academy, Bruna Stråket 16

41345 Göteborg, Sweden

Tel $+46-313427560$

Fax +4631826732

Email bjoern.redfors@wlab.gu.se 
Table I Preceding somatic or emotional stressors in the development of stress-induced cardiomyopathy

\begin{tabular}{|c|c|}
\hline Somatic stressors & Emotional stressors \\
\hline Vigorous exercise & Grief (eg, death or illness of a loved one) \\
\hline Pheochromocytoma & $\begin{array}{l}\text { Receiving bad news (eg, being } \\
\text { diagnosed with major illness, learning } \\
\text { of a daughter's divorce) }\end{array}$ \\
\hline Subarachnoid hemorrhage & Fear \\
\hline Seizure & Relationship conflicts \\
\hline Postoperative pain & Public speaking \\
\hline Hyperthyroidism & Financial problems \\
\hline Alcohol/opiate withdrawal & Being bullied \\
\hline Invasive medical procedures & Surprise party \\
\hline Exacerbation of underlying & Changing residence \\
\hline noncardiac disease & Involvement in accident \\
\hline \multicolumn{2}{|l|}{ Sexual intercourse } \\
\hline $\begin{array}{l}\text { Administration of } \\
\text { sympathomimetics }\end{array}$ & \\
\hline
\end{tabular}

an important role of catecholamines in the pathophysiology of SIC is the observation that plasma catecholamine levels are severely elevated in these patients, and SIC is common in patients with pheochromocytoma. ${ }^{7,8}$ In addition, iatrogenically administered beta-adrenoceptor agonists have been documented to trigger episodes. ${ }^{4}$ Last but not least, we and others have provoked SIC-like cardiac dysfunction in rats by exogenous administration of catecholamines. ${ }^{9,10}$

The short- and long-term prognoses of SIC patients were initially believed to be excellent, but recent reports indicate that SIC may be associated with significant mortality ${ }^{11-14}$ Data from Sahlgrenska University Hospital indicate a significant mortality in patients with SIC. ${ }^{14}$

\section{Definition of SIC}

One potential reason for underestimating the severity of the disease relates to the Mayo criteria which are often used to diagnose SIC (Table 2). ${ }^{3}$

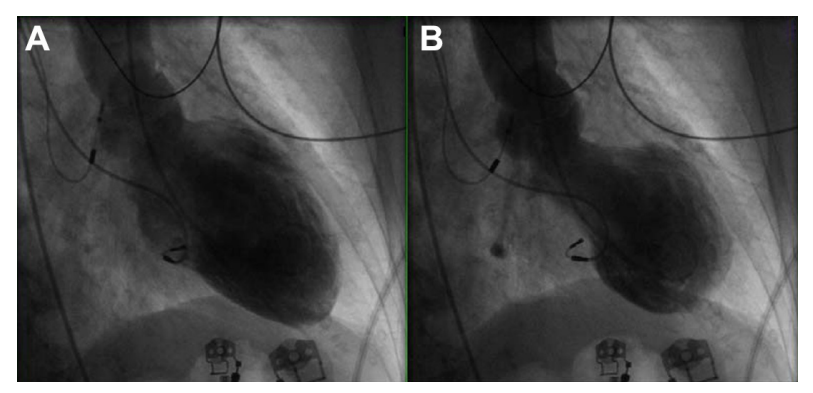

Figure I Midventricular variant of stress-induced cardiomyopathy. End-diastolic (A) and end-systolic (B) images of the left ventricle, obtained during ventriculography, in a patient with chest pain.

Note: Basal and apical function is preserved, whereas the midventricular regions are clearly akinetic.
In fact, when these interim criteria were first presented, the authors insightfully pointed out that the criteria would need to be revised in accordance with the growing knowledge about SIC. ${ }^{3}$ There is now considerable evidence for concomitant coronary artery disease and SIC. ${ }^{15-17}$ Strict adherence to the above criteria excludes all patients with significant coronary artery disease. Furthermore, any patient that dies acutely in SIC, by definition, cannot have "transient ventricular dysfunction" and may therefore not be diagnosed with SIC. Indeed, many publications have used "reversible cardiac dysfunction" as an inclusion criterion. The Mayo criteria may thus lead to an underestimation of the severity of this disease. Furthermore, if SIC is indeed mediated by stress-induced catecholamine toxicity, ${ }^{18,19}$ there is no good reason to exclude patients with pheochromocytoma. Instead, SIC should be recognized as a potential complication in these patients. There have been attempts at redefining these diagnostic criteria. ${ }^{17}$

Data from our hospital indicate a significant mortality in patients with SIC, and we have previously suggested the Gothenburg criteria for diagnosing SIC (Table 1). ${ }^{14}$ These criteria pertain to patients that survive the acute phase of SIC. Additional histological criteria for diagnosing SIC in patients who do not survive the acute phase would be desirable. Taken together, these clinical and histological criteria would allow for better design of clinical studies regarding SIC.

\section{Cardiac manifestations}

SIC typically presents as left-ventricular apical akinesia and systolic ballooning with preserved or hyperdynamic basal function. This pattern is reported in $>85 \%$ of all patients described in the literature. However, other types are increasingly being reported. ${ }^{1}$ It remains to be established whether the typical variant is the predominant type of stress-induced cardiac dysfunction or if it is simply more easily detected. It is possible that other types of SIC, as well as milder forms of "apical ballooning," occur without being recognized in the population. With so many preceding events described to trigger SIC, it is possible that different degrees of transient SIClike cardiac dysfunction may be rather common in the general population. In severe SIC cases, more than $2 / 3$ of the left ventricle may be affected, and such extensive cardiac dysfunction frequently leads to potentially fatal complications, including cardiogenic shock, ventricular rupture, ventricular fibrillation, and multiple organ dysfunction syndrome. However, observations from Sahlgrenska University Hospital indicate that in contrast to acute myocardial infarction, left-ventricular filling pressures are normal or near normal in SIC patients. 
Table 2 Myoclinic criteria and Gothenburg criteria in the diagnosis of stress-induced cardiomyopathy

\begin{tabular}{ll}
\hline Mayo clinic criteria ${ }^{3,42}$ & Gothenburg criteria' $^{14}$ \\
\hline $\begin{array}{l}\text { Transient hypokinesis, akinesis, or dyskinesis in the left ventricular } \\
\text { midsegments, with or without apical involvement; regional wall motion } \\
\text { abnormalities that extend beyond a single epicardial vascular } \\
\text { distribution; and frequently, but not always, a stressful trigger }\end{array}$ & $\begin{array}{l}\text { Transient hypokinesis, akinesis, or dyskinesis in the left-ventricular } \\
\text { segments and frequently, but not always, a stressful trigger } \\
\text { (psychical or physical) }\end{array}$ \\
$\begin{array}{l}\text { The absence of obstructive coronary disease or angiographic } \\
\text { evidence of acute plaque rupture }\end{array}$ & $\begin{array}{l}\text { The absence of other pathological conditions (eg, ischemia, } \\
\text { myocarditis, toxic damage, tachycardia, etc) that may more credibly } \\
\text { elevation and/or T-wave inversion) or modest elevation in }\end{array}$ \\
$\begin{array}{l}\text { cardiac troponin } \\
\text { The absence of pheochromocytomal dysfunction }\end{array}$ \\
\hline
\end{tabular}

Furthermore, cardiac dysfunction is completely or almost completely reversible if the patient survives the acute phase. In fact, cardiac function typically normalizes within a few days or weeks. ${ }^{14}$

Beyond adrenergic overstimulation, our understanding of the pathophysiology underlying the cardiac dysfunction is limited. Among the proposed hypotheses are coronary artery spasm, microvascular dysfunction, outflow tract obstruction, and direct effects of catecholamine on the myocardium. ${ }^{20}$ One hypothesis postulates that regional contractile dysfunction is protective, rather than detrimental, in the setting of severe myocardial catecholamine overstimulation. ${ }^{20}$ Perhaps even more intriguing than the development of this peculiar type of extensive cardiac dysfunction, is the apparently complete recovery observed in most patients. Elucidation of the selfhealing mechanisms, at the cellular and at the systemic level, behind the recovery could have implications across the spectrum of cardiovascular disease.

\section{SIC beyond the heart}

It is not unusual for a SIC patient to survive an episode in which the akinesia involves $>50 \%$ of the left ventricle. In the setting of acute myocardial infarction, loss of function of that magnitude would most likely result in death. ${ }^{21}$ Such a contradictory finding highlights the enigmatic nature of SIC. We hypothesized that compensatory cardiocirculatory mechanisms are activated to maintain sufficient perfusion of the vital organs in this setting and showed that SIC was associated with decreased sympathetic tone, decreased peripheral vascular resistance, and preserved cardiac output. ${ }^{14}$ These findings differ from that observed in acute myocardial infarction and would be consistent with our observation of near-normal filling pressures in SIC. Indeed, if one considers that one distinctive hallmark of SIC appears to be severely elevated plasma levels of catecholamines, it may be reasonable to view SIC as a condition that is associated with cardiac as well as extracardiac changes. In addition to its unique cardiocirculatory profile, SIC may be intimately linked to other organ systems. In the remainder of this manuscript we turn our attention to the close relationship between the brain and the heart, in SIC.

\section{SIC and the brain}

The common denominator for the different factors shown to trigger SIC appears to be the activation of the sympatico-adrenal system. Although the many triggering events described to date are diverse, they can be arbitrarily divided into two categories, namely, emotional and somatic stressors; these categories can be considered as different elements

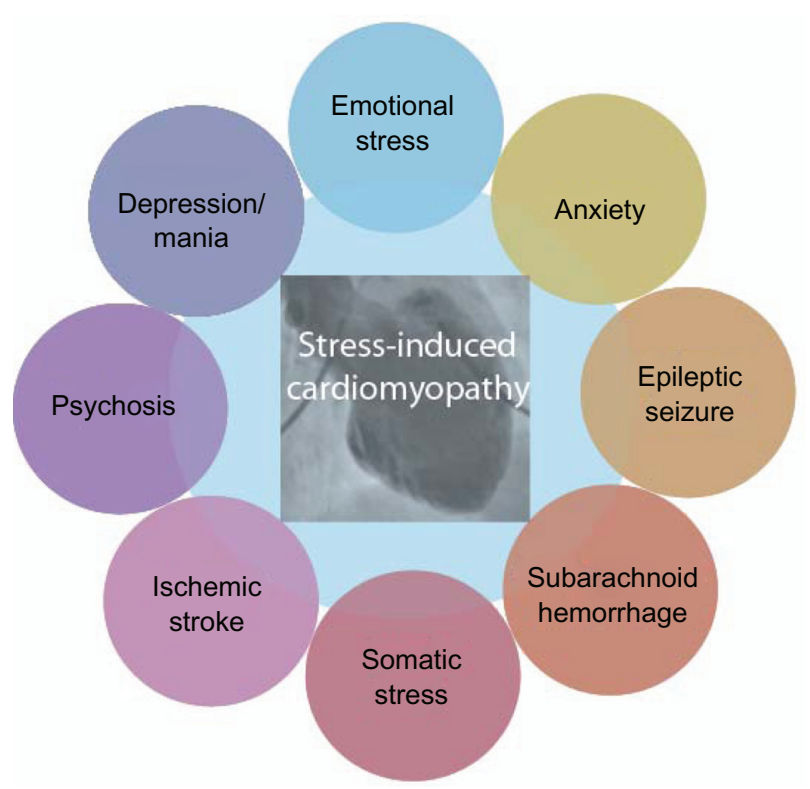

Figure 2 Connection between stress-induced cardiomyopathy (SIC) and neuropsychiatry.

Notes: A somatic and/or emotional stressor can be identified in most SIC patients. Although these stressors are often categorized as either emotional or somatic, they could also be viewed as elements of a continuous spectrum of stressors able to induce SIC. 
of a continuous spectrum, linked through the interface of neurology and psychiatry (Figure 2).

Indeed, cardiac protein release and reversible leftventricular dysfunction are common in patients with an acute intracranial episode. ${ }^{22-24}$

Several recent case reports have highlighted the connection between subarachnoid hemorrhage (SAH) and SIC. ${ }^{25,26}$ Similar degenerative postmortem histological findings were seen in the hearts of SAH patients, as in patients with SIC and pheochromocytoma. ${ }^{7,27}$ Consistent with observations in the general SIC cohort, among patients that presented with SAH, release of cardiospecific proteins was much more common in women. Furthermore, in a multivariate analysis that also included ejection fraction, cardiac protein release was associated with lower systolic blood pressure. ${ }^{22}$

Much like SAH, ischemic stroke is intimately linked to SIC. ${ }^{28}$ Elevated plasma levels of cardiac proteins are present in almost $20 \%$ of these patients, and cardiac protein release is associated with poor prognosis. ${ }^{29}$ In a recent report that included 569 patients with ischemic stroke and that used apical akinesia as an obligate criterion, SIC occurred in $1.2 \%(\mathrm{n}=7)$, all of whom were women. ${ }^{28}$ Cardiac function recovered within 3 weeks. The reader should note that restricting the diagnosis of SIC to patients presenting with the typical apical variant may have caused the authors to underestimate the prevalence of SIC in these patients. There exists a two-way relationship between ischemic stroke and SIC, in the sense that ischemic stroke may be either the cause or the consequence of SIC. ${ }^{30-32}$ Although thrombus formation may occur rather frequently within the akinetic left ventricle, thromboembolic complications appear to be less common. ${ }^{33}$ Short-term antithrombotic therapy should, nevertheless, be considered in SIC patients, especially in those patients that present with the typical apical variant. ${ }^{33,34}$

The third group of intracranial events that has been documented to trigger SIC is epileptic seizures. Also, these patients display the SIC phenotype, with left ventricular apical akinesia and typical patchy myocardial lesions. ${ }^{35}$ Similar to the situation in patients with SAH and ischemic stroke, as well as in the general SIC cohort, women are overrepresented among epileptic patients that develop SIC. ${ }^{36}$ The finding that SIC secondary to epilepsy appears to be particularly associated with more severe complications has led some authors to speculate that SIC may explain some cases of unexpected sudden death in epilepsy. ${ }^{36}$ We don't believe it to be a great leap to go from the intimate relationship between
SIC and acute lesions of higher cerebral centers, including the insular area, ${ }^{28}$ to the relationship between SIC and emotional stressors.

The fact that acute severe emotional stress can trigger SIC has been known since the syndrome was first described, and this observation led to the coining of the terms "stressinduced cardiomyopathy" and "broken heart syndrome." Two recent extensive overviews of American SIC cohorts found that anxiety and chronic stress were both associated

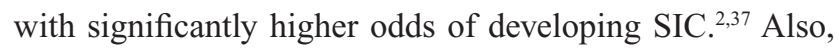
depression was associated with near-significantly increased odds of developing SIC. ${ }^{2}$ This is consistent with a previous report that found an increased prevalence of premorbid psychiatric diagnoses, particularly anxiety disorders, in SIC patients. ${ }^{38}$ These findings are intriguing, as they imply that chronic stress and impaired well-being may predispose an individual to develop SIC. If this is indeed the case, it adds to the evidence that SIC spans the domains of psychiatric as well as somatic medicine, highlighting the inherent link between the two. One survey found that almost $16 \%$ of postmenopausal women reported significant depressive symptoms and that depressive symptoms were associated with cardiovascular events. ${ }^{39}$ Again, this is the typical SIC patient category. Indeed, chronic stress and depression have both been shown to cause structural changes to the cerebrum, including decreased volume of the hippocampus and loss of grey matter in the prefrontal and cingulate cortices. Furthermore, these structural changes have been linked to alterations in the hypothalamic-pituitary-adrenal axis response to stress. ${ }^{40} \mathrm{We}$ believe that SIC may occur acutely in biologically predisposed individuals in response to an acute stressor and that this biological predisposition may, in turn, be caused by chronic stress or impaired well-being.

Psychiatric conditions may not only predispose an individual to develop SIC in response to a strong emotional and/or somatic stressor, there have been published reports describing exacerbations of psychiatric illnesses that have, in themselves, acutely triggered SIC. ${ }^{41}$

We propose that SIC be viewed as a cardiocirculatory syndrome that is intimately linked to other organs, perhaps most importantly the brain. Because SIC is a potential complication of, among others, neurological and psychiatric conditions, we believe that increased awareness of the syndrome is desirable, not only among cardiologists but also among other specialists. Although the treatment of SIC is the task of the cardiologist, successful prevention, and to some extent, early detection, may sometimes lie in the hands of other physicians. 


\section{Disclosure}

The authors report no conflicts of interest in this work.

\section{References}

1. Shao Y, Redfors B, Lyon AR, Rosengren A, Swedberg K, Omerovic E. Trends in publications on stress-induced cardiomyopathy. Int J Cardiol. 2012;157(3):435-436.

2. Deshmukh A, Kumar G, Pant S, Rihal C, Murugiah K, Mehta JL. Prevalence of Takotsubo cardiomyopathy in the United States. Am Heart J. 2012;164(1):66-71.

3. Prasad A, Lerman A, Rihal CS. Apical ballooning syndrome (Tako-Tsubo or stress cardiomyopathy): a mimic of acute myocardial infarction. Am Heart J. 2008;155(3):408-417.

4. Abraham J, Mudd JO, Kapur NK, Klein K, Champion HC, Wittstein IS. Stress cardiomyopathy after intravenous administration of catecholamines and beta-receptor agonists. J Am Coll Cardiol. 2009;53(15) 1320-1325.

5. Johnson NP, Chavez JF, Mosley WJ 2nd, Flaherty JD, Fox JM. Performance of electrocardiographic criteria to differentiate Takotsubo cardiomyopathy from acute anterior ST elevation myocardial infarction. Int J Cardiol. Epub July 28, 2011.

6. Ahmed KA, Madhavan M, Prasad A. Brain natriuretic peptide in apical ballooning syndrome (Takotsubo/stress cardiomyopathy): comparison with acute myocardial infarction. Coron Artery Dis. 2012;23(4): 259-264.

7. Wittstein IS, Thiemann DR, Lima JA, et al. Neurohumoral features of myocardial stunning due to sudden emotional stress. $N$ Engl $J$ Med. 2005;352(6):539-548.

8. Park JH, Kim KS, Sul JY, et al. Prevalence and patterns of left ventricular dysfunction in patients with pheochromocytoma. J Cardiovasc Ultrasound. 2011;19(2):76-82.

9. Shao Y, Redfors B, Scharin Täng M, et al. Novel rat model reveals important roles of $\beta$-adrenoreceptors in stress-induced cardiomyopathy. Int J Cardiol. Epub January 25, 2013.

10. Paur H, Wright PT, Sikkel MB, et al. High levels of circulating epinephrine trigger apical cardiodepression in a $\beta 2$-adrenergic receptor/ Gi-dependent manner: a new model of Takotsubo cardiomyopathy. Circulation. 2012;126(6):697-706.

11. Sharkey SW, Windenburg DC, Lesser JR. Natural history and expansive clinical profile of stress (tako-tsubo) cardiomyopathy. J Am Coll Cardiol. 2010;55(4):333-341.

12. Lee PH, Song JK, Sun BJ. Outcomes of patients with stress-induced cardiomyopathy diagnosed by echocardiography in a tertiary referral hospital. J Am Soc Echocardiogr. 2010;23(7):766-771.

13. Burgdorf C, Kurowski V, Bonnemeier H, Schunkert H, Radke PW. Longterm prognosis of the transient left ventricular dysfunction syndrome (Tako-Tsubo cardiomyopathy): focus on malignancies. Eur J Heart Fail. 2008;10(10):1015-1019.

14. Schultz T, Shao Y, Redfors B, et al. Stress-induced cardiomyopathy in Sweden: evidence for different ethnic predisposition and altered cardio-circulatory status. Cardiology. 2012;122(3):180-186.

15. Haghi D, Papavassiliu T, Hamm K, Kaden JJ, Borggrefe M, Suselbeck T. Coronary artery disease in takotsubo cardiomyopathy. Circ J. 2007; 71(7):1092-1094.

16. Kurisu S, Inoue I, Kawagoe T. Prevalence of incidental coronary artery disease in tako-tsubo cardiomyopathy. Coron Artery Dis. 2009;20(3) 214-218.

17. Gaibazzi N, Ugo F, Vignali L, Zoni A, Reverberi C, Gherli T. Tako-Tsubo cardiomyopathy with coronary artery stenosis: a case-series challenging the original definition. Int J Cardiol. 2009;133(2):205-212.

18. Akashi YJ, Nakazawa K, Sakakibara M, Miyake F, Koike H, Sasaka K. The clinical features of takotsubo cardiomyopathy. QJM. 2003;96(8): 563-573.

19. Park JH, Kang SJ, Song JK, et al. Left ventricular apical ballooning due to severe physical stress in patients admitted to the medical ICU. Chest. 2005;128(1):296-302.
20. Lyon AR, Rees PS, Prasad S, Poole-Wilson PA, Harding SE. Stress (Takotsubo) cardiomyopathy - a novel pathophysiological hypothesis to explain catecholamine-induced acute myocardial stunning. Nat Clin Pract Cardiovasc Med. 2008;5(1):22-29.

21. Page DL, Caulfield JB, Kastor JA, DeSanctis RW, Sanders CA. Myocardial changes associated with cardiogenic shock. New Engl J Med. 1971;285(3):133-137.

22. Tung P, Kopelnik A, Banki N, et al. Predictors of neurocardiogenic injury after subarachnoid hemorrhage. Stroke. 2004;35(2):548-551.

23. Kono T, Morita H, Kuroiwa T, Onaka H, Takatsuka H, Fujiwara A. Left ventricular wall motion abnormalities in patients with subarachnoid hemorrhage - neurogenic stunned myocardium. J Am Coll Cardiol. 1994;24(3):636-640.

24. Simon RP, Aminoff MJ, Benowitz NL. Changes in plasma catecholamines after tonic-clonic seizures. Neurology. 1984;34(2):255-257.

25. Ennezat PV, Pesenti-Rossi D, Aubert JM, et al. Transient left ventricular basal dysfunction without coronary stenosis in acute cerebral disorders: a novel heart syndrome (inverted Takotsubo). Echocardiography. 2005; 22(7):599-602.

26. Das M, Gonsalves S, Saha A, Ross S, Williams G. Acute subarachnoid haemorrhage as a precipitant for takotsubo cardiomyopathy: a case report and discussion. Int J Cardiol. 2009;132(2):283-285.

27. Doshi R, Neil-Dwyer G. Hypothalamic and myocardial lesions after subarachnoid haemorrhage. J Neurol Neurosurg Psychiatry. 1977;40(8): 821-826.

28. Yoshimura S, Toyoda K, Ohara T, et al. Takotsubo cardiomyopathy in acute ischemic stroke. Ann Neurol. 2008;64(5):547-554.

29. Kerr G, Ray G, Wu O, Stott DJ, Langhorne P. Elevated troponin after stroke: a systematic review. Cerebrovasc Dis. 2009;28(3): 220-226.

30. Shin SN, Yun KH, Ko JS, et al. Left ventricular thrombus associated with takotsubo cardiomyopathy: a cardioembolic cause of cerebral infarction. J Cardiovasc Ultrasound. 2011;19(3):152-155.

31. de Gregorio C, Grimaldi P, Lentini C. Left ventricular thrombus formation and cardioembolic complications in patients with Takotsubolike syndrome: a systematic review. Int J Cardiol. 2008;131(1): $18-24$

32. Leurent G, Larralde A, Boulmier D, et al. Cardiac MRI studies of transient left ventricular apical ballooning syndrome (takotsubo cardiomyopathy): a systematic review. Int J Cardiol. 2009;135(2): 146-149.

33. Haghi D, Papavassiliu T, Heggemann F, Kaden JJ, Borggrefe M, Suselbeck T. Incidence and clinical significance of left ventricular thrombus in tako-tsubo cardiomyopathy assessed with echocardiography QJM. 2008;101(5):381-386.

34. Jabara R, Gadesam R, Pendvala L, Chronos N, King SB, Chen JP. Comparison of the clinical characteristics of apical and non-apical variants of "broken heart" (takotsubo) syndrome in the United States. J Invasive Cardiol. 2009;21(5):216-222.

35. Shimizu M, Kagawa A, Takano T, Masai H, Miwa Y. Neurogenic stunned myocardium associated with status epilepticus and postictal catecholamine surge. Intern Med. 2008;47(4):269-273.

36. Stöllberger C, Wegner C, Finsterer J. Seizure-associated Takotsubo cardiomyopathy. Epilepsia. 2011;52(11):e160-e167.

37. El-Sayed AM, Brinjikji W, Salka S. Demographic and co-morbid predictors of stress (takotsubo) cardiomyopathy. Am J Cardiol. 2012;110(9): $1368-1372$.

38. Summers MR, Lennon RJ, Prasad A. Pre-morbid psychiatric and cardiovascular diseases in apical ballooning syndrome (tako-tsubo/ stress-induced cardiomyopathy): potential pre-disposing factors? J Am Coll Cardiol. 2010;55(7):700-701.

39. Wassertheil-Smoller S, Shumaker S, Ockene J, et al. Depression and cardiovascular sequelae in postmenopausal women. The Women's Health Initiative (WHI). Arch Intern Med. 2004;164(3):289-298.

40. Gianaros PJ, Jennings JR, Sheu LK, Greer PJ, Kuller LH, Matthews KA. Prospective reports of chronic life stress predict decreased grey matter volume in the hippocampus. Neuroimage. 2007;35(2):795-803. 
41. Corrigan FE 3rd, Kimmel MC, Jayaram G. Four cases of takotsubo cardiomyopathy linked with exacerbations of psychiatric illness. Innov Clin Neurosci. 2011;8(7):50-53.
42. Elmir Omverovic. How to think about stress-induced cardiomyopathy? Think "out of the box"! Scand Cardiovasc J. 2011;45(2):67-71.

\section{Publish your work in this journal}

Vascular Health and Risk Management is an international, peerreviewed journal of therapeutics and risk management, focusing on concise rapid reporting of clinical studies on the processes involved in the maintenance of vascular health; the monitoring, prevention and treatment of vascular disease and its sequelae; and the involvement of metabolic disorders, particularly diabetes. This journal is indexed on PubMed Central and MedLine. The manuscript management system is completely online and includes a very quick and fair peer-review system, which is all easy to use. Visit http://www.dovepress.com/ testimonials.php to read real quotes from published authors.

Submit your manuscript here: http://www.dovepress.com/vascular-health-and-risk-management-journal 